\title{
Erratum to: Achieving Population-Level Change Through a System-Contextual Approach to Supporting Competent Parenting
}

\author{
Matthew R. Sanders ${ }^{1,2}$ (1) Kylie Burke $^{1} \cdot$ Ronald J. Prinz $^{2} \cdot$ Alina Morawska $^{1}$
}

Published online: 18 March 2017

(c) Springer Science+Business Media New York 2017

\section{Erratum to: Clin Child Fam Psychol Rev \\ DOI 10.1007/s10567-017-0227-4}

The original version of this article unfortunately contained a mistake. The conflict of interest statement was missing in the article. The CoI statement is given below.

\section{Compliance with Ethical Standards}

Conflict of interest The Parenting and Family Support Centre is partly funded by royalties stemming from published resources of the Triple P-Positive Parenting Program, which is developed and owned by the University of Queensland (UQ). Royalties are also distributed to the Faculty of Health and Behavioural Sciences at UQ and contributory authors of published Triple P resources. Triple P International (TPI) Pty Ltd is a private company licensed by Uniquest Pty Ltd on behalf of UQ, to publish and disseminate Triple P worldwide. The authors of this report have no share or ownership of TPI. Burke does not currently but may in the future receive royalties from TPI. Morawska receives royalties from TPI. Sanders receives royalties and consultancy fees from TPI. Prinz is a consultant to TPI. TPI had no involvement in the study design, collection, analysis or interpretation of data, or writing of this report. Burke, Morawska, and Sanders are employees at UQ.

The online version of the original article can be found under doi:10.1007/s10567-017-0227-4.

Matthew R. Sanders

m.sanders@psy.uq.edu.au

1 Parenting and Family Support Centre, The University of Queensland, Brisbane, QLD 4072, Australia

2 University of South Carolina, Columbia, SC, USA 